\title{
Single Pleural Relapse of a Nasal-Type Extranodal Natural Killer/T-Cell Lymphoma: A Case Report
}

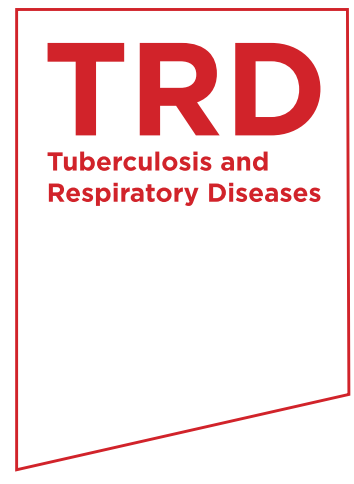

\author{
Keunmo Kim, M.D. ${ }^{1}$, Youngmin Oh, M.D. ${ }^{1}$, Sung-Nam Lim, M.D. ${ }^{1}$, Song-Yi Choi, M.D., Ph.D. ${ }^{2}$, Ok- \\ Jun Lee, M.D., Ph.D. ${ }^{2}$, Kang-Hyeon Choe, M.D., Ph.D. ${ }^{1}$, Ki-Man Lee, M.D., Ph.D. ${ }^{1}$ and Jin-Young \\ An, M.D. ${ }^{1}$ \\ Departments of ${ }^{1}$ Internal Medicine and ${ }^{2}$ Pathology, Chungbuk National University College of Medicine, Cheongju, Korea
}

A nasal-type extranodal natural killer/T-cell lymphoma is considered an aggressive form of non-Hodgkin's lymphoma, with approximately half of all patients relapsing during the follow-up period, and most relapses occurring within the first 2 years of remission. Here we report an unusual case of a 42-year-old man who experienced recurrence in single pleura after 8 years of remission.

Keywords: Pleural Effusion; Adenosine Deaminase; Lymphoma, Extranodal NK-T-Cell

\section{Introduction}

Extranodal natural killer (NK)/T-cell lymphoma is a subtype of lymphoma that is derived from NK cells and is relatively more common in Asia than in Western countries ${ }^{1}$. NK/T-cell lymphoma considered an aggressive form of non-Hodgkin's lymphoma (NHL) ${ }^{2}$. Approximately half of all patients relapse during the follow-up period, and relapsed NK/T-cell lymphoma patients often show a fulminant clinical course that is refractory to conventional chemotherapy. Most relapses of NK/

Address for correspondence: Jin-Young An, M.D.

Department of Internal Medicine, Chungbuk National University College of Medicine, 776 ilsunhwan-ro, Heungdeok-gu, Cheongju 361-711, Korea

Phone: 82-43-269 -6308, Fax: 82-43-273-3252

E-mail:drahnjy@chungbuk.ac.kr

Received: Sep. 13, 2013

Revised: Sep. 30, 2013

Accepted: Oct. 1, 2013

(c) It is identical to the Creative Commons Attribution Non-Commercial License (http://creativecommons.org/licenses/by-nc/3.0/).

Copyright (c) 2014

The Korean Academy of Tuberculosis and Respiratory Diseases. All rights reserved.
T-cell lymphoma occur within the first 2 years of remission ${ }^{3}$. However, rare cases of relapse in NK/T-cell lymphoma, nasal type have been described after many years of remission ${ }^{4}$. Such late relapses are so rare that practically nothing is known about them.

We describe an unusual case of a 42-year-old man who experienced recurrence after 8 years of remission. The patient presented with pleural effusion involving Epstein-Barr virus (EBV)-positive NHL cells of the NK/T-cell lineage.

\section{Case Report}

A 42-year-old man was admitted to the hospital after experiencing fever and night sweating for 2 weeks. He had visited another hospital 1 month earlier because of pain on the left side of his chest. At this hospital, he underwent chest radiography and computed tomography (CT), which showed a left pleural effusion. Diagnostic thoracentesis was performed, yielding $200 \mathrm{~mL}$ of clear, yellow-colored pleural fluid. Analysis of the pleural fluid revealed an exudative pattern; a protein level of 5.3 $\mathrm{g} / \mathrm{dL}$ (serum protein level, $7.5 \mathrm{~g} / \mathrm{dL}$ ), a lactate dehydrogenase (LDH) level of $273 \mathrm{IU} / \mathrm{L}$ (serum LDH level, $342 \mathrm{IU} / \mathrm{L}$ ), a glucose level of $61 \mathrm{mg} / \mathrm{dL}$, an albumin level of $3.3 \mathrm{~g} / \mathrm{dL}$, and a $\mathrm{pH}$ of 7.3. The pleural fluid cell count was 2,560 cells $/ \mathrm{mL}$, with $10 \%$ polymorphonuclear cells, $90 \%$ lymphocytes, and an adenosine deaminase (ADA) concentration of $82 \mathrm{IU} / \mathrm{L}$. No malignant 

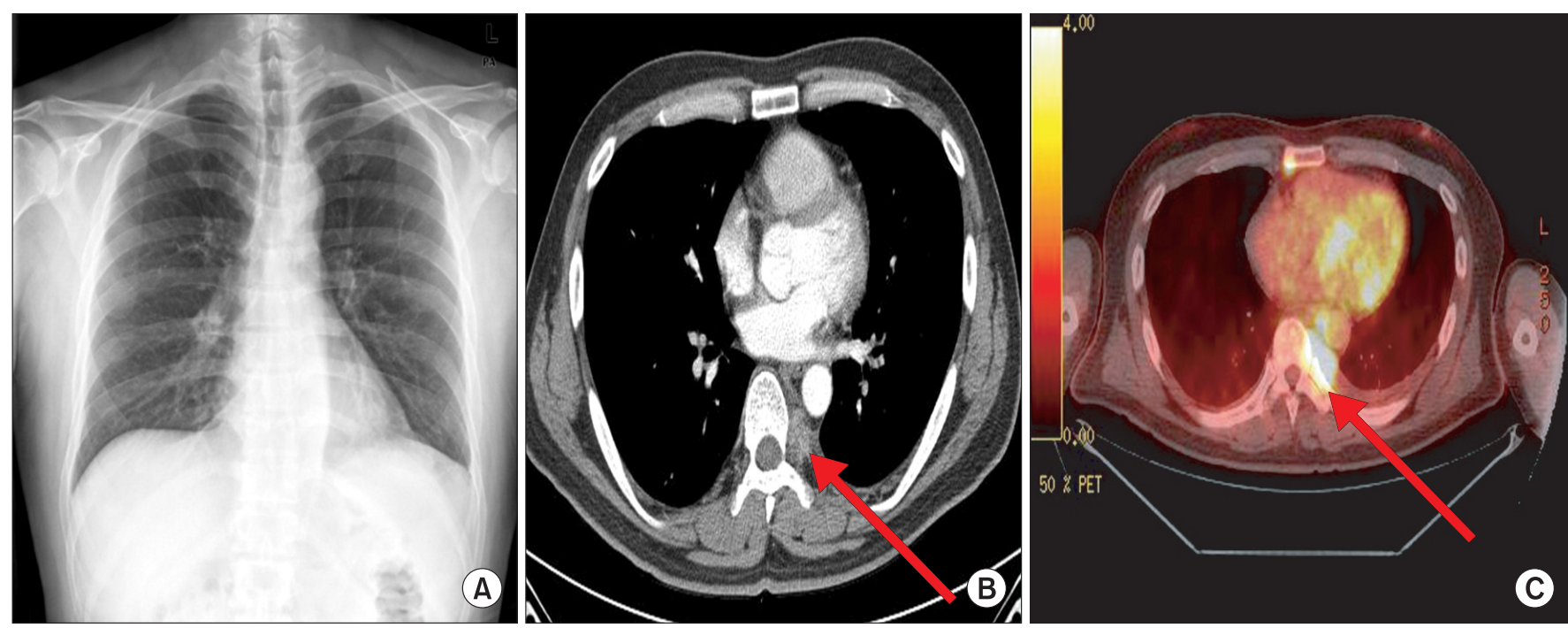

Figure 1. (A) A chest radiograph showing costophrenic angle blunting, consistent with a small amount of pleural effusion. (B) A chest computed tomography (CT) scan showing an enhanced heterogeneous mass-like lesion in the left eight paravetebral area. (C) ${ }^{18} \mathrm{~F}-f l u o r o d e o x y-$ glucose (FDG)-positron-emission tomography revealed an intense FDG uptake at the same site as on the CT.

cells were observed on cytological analysis. Bacterial, fungal, and mycobacterial cultures of the pleural fluid were also negative. The patient was diagnosed with tuberculous pleurisy and was administered anti-tuberculosis medications. After treatment, the pleural effusion and chest pain disappeared and the patient was discharged from the hospital. However, 2 weeks later, he developed new symptoms of fever, chills, and night sweating, which caused worry because of the patient's past illness. Eight years ago, he was diagnosed with extranodal NK/ T-cell lymphoma, nasal type. He had been successfully treated with treatment with a combined of chemotherapy and radiotherapy resulting in a complete remission without recurrence. Upon admission, the patient's vital signs were stable, except for the presence of fever. In addition, laboratory findings were within the normal range. A chest radiograph showed findings consistent with a small amount of pleural effusion (Figure 1A). A chest CT scan revealed an heterogeneously enhancedmass to the left of the eight thoracic spines (Figure 1B). A subsequent ${ }^{18} \mathrm{~F}$-fluorodeoxyglucose $\left({ }^{18} \mathrm{~F}\right.$-FDG)-positron emission tomography revealed FDG activity at the same site (Figure 1C). A biopsy using video-assisted thoracic surgery was performed. Subsequent analysis by microscopy showed that the pleural tissue was diffusely infiltrated with atypical lymphoid cells (Figure 2A). It was CD3 +, CD56 +, granzyme B + , and EBV + (Figure 2C-F). These histological features were corresponded with the previous biopsy from nasal cavity eight years ago (Figure 2G, H). This led us to diagnose the patient's condition as recurrent pleural recurrence of extranodal NK/ T-cell lymphoma. He has been been undergoing sequential chemotherapy followed by autologous hematopoietic stem cell transplantation.

\section{Discussion}

According to the new World Health Organization classification, extranodal NK/T-cell lymphoma, nasal type is classified as a subtype of peripheral T-cell lymphoma ${ }^{5}$. NK/T-cell lymphomas show a specific geographical predilection for Asia. And in Korea, 9-12\% of all NHLs are NK/T-cell lymphomas . NK/T-cell lymphomas are considered an aggressive form of NHL, approximately $50 \%$ of patients relapse during the followup $^{3}$. Common relapse sites include nasal sites and its adjacent structures; however, relapse also occurs at distant sites throughout the whole body.

In this case study, NK/T-cell lymphoma recurred with tuberculosis-like symptoms and left pleural effusion after 8 years of remission. The tumor clinically mimicked pulmonary tuberculosis as it presented with pleural effusion without lymphadenopathy, organomegaly, or an extranodal mass. Pleural fluid analysis revealed exudates with a predominance of lymphocytes and high ADA levels. On the basis of these results, the patient was diagnosed with tuberculosis and the initial symptoms disappeared after anti-tuberculosis treatment. However, these symptoms reappeared during the antituberculosis treatment, and the final diagnosis was NK/T-cell lymphoma, nasal type, which recurred 8 years after the first remission.

Tuberculous pleurisy is an important differential diagnosis when assessing lymphocytic pleural effusions with high ADA levels in patients with pleural effusion. However, pleural effusion is a relatively common finding in patients with NHL, occurring in up to $20 \%$ of cases ${ }^{7}$. However, the rate of positive cytological findings varies widely $(22-94 \%)^{8}$. Tuberculous 

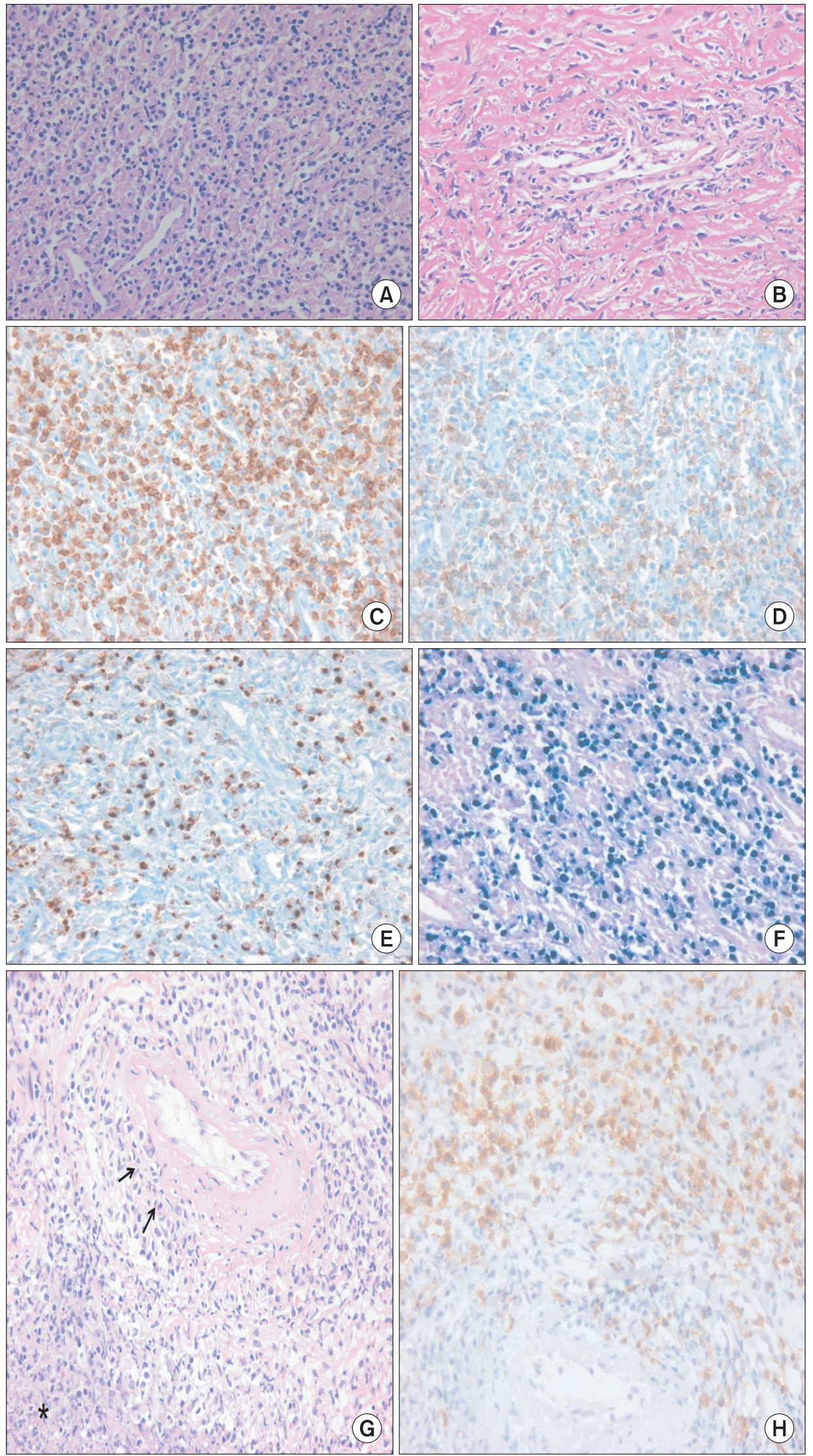

Figure 2. Pleural involvement of extranodal natural killer/T-cell lymphoma, nasal type. (A) Atypical lymphocytes of small to medium size are diffusely infiltrated in pleural tissue (H\&E stain, $\times 200$ ). (B) The infiltrate shows an angiocentric growth pattern $(H \& E$ stain, $\times 200)$. (C-E) The neoplastic cells shows positive reactivity for CD3 (C, $\times 200)$, CD56 (D, $\times 200)$, and granzyme $\mathrm{B}(\mathrm{E}, \times 200)$ by immunohistochemical staining. (F) Epstein-Barr virus in situ hybridization reveals nuclear positivity blue color $(\times 200)$. (G) The initial biopsy from the nasal cavity showed proliferation of atypical lymphoid cells with extensive necrosis (asterisk), angiocentric growth pattern (arrows) and mild pleomorphism $(H \& E$ stain, $\times 200)$. $(H)$ The neoplastic cells revealed immunoreactivity for CD56 antibody $(\times 200)$. 
pleurisy accounts for $25 \%$ of all cases of pleural effusion ${ }^{9}$. Although a definitive diagnosis of tuberculous pleurisy relies on polymerase chain reaction (PCR), a stain or culture of tubercle bacilli from pleural fluid, or pleural biopsy, these tests have limited sensitivity ${ }^{10}$. A diagnosis can also be established with reasonable certainty on the basis of elevated ADA levels in pleural fluid or pathologic findings in the pleura, including granulomas and Langerhans-type giant cells. However, patients with pyothorax, rheumatoid arthritis, malignant lymphoma, or other maliginancies may also exhibit elevated ADA levels ${ }^{11}$. Although pleural effusion was controlled and the patient was afebrile after anti-tuberculosis therapy, the primary etiology of elevated ADA levels in the presented case was presumed to be NK/T-cell lymphoma.

In Korea, the prevalence of pulmonary tuberculosis has been high until recently, and tuberculous pleurisy is also common. Wu et al. ${ }^{12}$ reported that the hazard ratio of tuberculosis was 3.22 in patients with hematological malignancies, including NHL and leukemia, compared to healthy individuals.

In rare cases, the co-existence of malignant lymphoma and tuberculosis has been reported ${ }^{13,14}$. Most of these cases were of pulmonary tuberculosis or lymph node tuberculosis. Reports of co-existing malignant lymphoma with tuberculous pleurisy are rare. However, considering the clinical findings, including negative findings for tuberculosis on PCR of pleural effusion and no effect of anti-tuberculosis treatment, it can explained that the origin of the pleural effusion was not tuberculosis but NK/T-cell lymphoma.

Although pleural fluid ADA analysis is very easy, cheap, and highly sensitive and specific test for diagnosis of tuberculous pleurisy, we should know that it can be increased in some of malignancy such as lymphoma, lung carcinoma, colorectal carcinoma, acute lymphoid leukemia, and mesotheolioma ${ }^{11}$. So we should pay attention to false positive increase of pleural ADA activity in tuberculosis pleurisy diagnosis. The case presented here demonstrated the importance of considering the possibility malignancy in exudative pleural effusion patient with a predominance of lymphocytes and high ADA levels.

\section{Conflicts of Interest}

No potential conflict of interest relevant to this article was reported.

\section{References}

1. Lee J, Suh C, Park YH, Ko YH, Bang SM, Lee JH, et al. Extranodal natural killer T-cell lymphoma, nasal-type: a prognostic model from a retrospective multicenter study. J Clin Oncol 2006;24:612-8.

2. Kim GE, Cho JH, Yang WI, Chung EJ, Suh CO, Park KR, et al. Angiocentric lymphoma of the head and neck: patterns of systemic failure after radiation treatment. J Clin Oncol 2000;18:54-63.

3. Kwong YL. Natural killer-cell malignancies: diagnosis and treatment. Leukemia 2005;19:2186-94.

4. Au WY, Kim SJ, Yiu HH, Ngan RK, Loong F, Kim WS, et al. Clinicopathological features and outcome of late relapses of natural killer cell lymphomas 10-29 years after initial remission. Am J Hematol 2010;85:362-3.

5. Jaffe ES. The 2008 WHO classification of lymphomas: implications for clinical practice and translational research. Hematology Am Soc Hematol Educ Program 2009:523-31.

6. Kim J, Kim EY, Lee SK, Kim DI, Kim CH, Kim SH, et al. Extranodal nasal-type NK/T-cell lymphoma: computed tomography findings of head and neck involvement. Acta Radiol 2010;51:164-9.

7. Berkman N, Breuer R, Kramer MR, Polliack A. Pulmonary involvement in lymphoma. Leuk Lymphoma 1996;20:229-37.

8. Das DK. Serous effusions in malignant lymphomas: a review. Diagn Cytopathol 2006;34:335-47.

9. Valdes L, Alvarez D, Valle JM, Pose A, San Jose E. The etiology of pleural effusions in an area with high incidence of tuberculosis. Chest 1996;109:158-62.

10. Valdes L, Alvarez D, San Jose E, Penela P, Valle JM, GarciaPazos JM, et al. Tuberculous pleurisy: a study of 254 patients. Arch Intern Med 1998;158:2017-21.

11. Lee YC, Rogers JT, Rodriguez RM, Miller KD, Light RW. Adenosine deaminase levels in nontuberculous lymphocytic pleural effusions. Chest 2001;120:356-61.

12. Wu CY, Hu HY, Pu CY, Huang N, Shen HC, Li CP, et al. Aerodigestive tract, lung and haematological cancers are risk factors for tuberculosis: an 8-year population-based study. Int J Tuberc Lung Dis 2011;15:125-30.

13. Falagas ME, Kouranos VD, Athanassa Z, Kopterides P. Tuberculosis and malignancy. QJM 2010;103:461-87.

14. Lanjewar DN, Lanjewar SD, Chavan G. Coexistent lymphoma with tuberculosis and Kaposi's sarcoma with tuberculosis occurring in lymph node in patients with AIDS: a report of two cases. Indian J Pathol Microbiol 2010;53:551-4. 